This is a preprint of article Huvila, I. Participatory archive: towards decentralised curation, radical user orientation and broader contextualisation of records management. Archival Science, 2008, 8 (1), 15-36. (Springer).

\title{
Participatory archive: towards decentralised curation, radical user orientation, and broader contextualisation of records management
}

Isto Huvila

Information Studies, Ảbo Akademi University, Tavastgatan 13, FI-20500 ABO, Finland and Cultural Sciences, Lund University, Sweden

isto.huvila@abo.fi

The user perspective and user studies have received noticeably little practical attention in archives and archival science. The purpose of this article is to address the issues of communication and user participation in archival contexts. Two action research projects based digital archives are discussed. The insights gained during the research and development work are used to formulate a new approach to a participatory archive. In spite of the historical nature of the archives discussed, the suggested ways of interacting with an archives are not specific to historical records. The fundamental characteristics of the proposed approach are decentralised curation, radical user orientation, and contextualisation of both records and the entire archival process.

Keywords : digital archives, paarticipatory archives, user studies, user orientation, wikis

\section{Introduction}

In different memory institutions (archives, libraries and museums), the concern for users and uses of resources varies considerably. Generally speaking, the interest in users' needs has been strongest in libraries and especially in library and information science (LIS) research. People go to a library to find out something they need to know, to find a book they might be interested in, or to do something they feel they need or want to do. Even though library users are definitely not a 
representative sample of the population, the premise is that libraries should have something to offer for everybody: for both motorcycle enthusiasts and poetry lovers (Buckland 1992). While the earlier user oriented paradigm saw librarians as information providers and users as receivers, recent discussions about library 2.0 have underlined the need to get users involved in the library in a more profound and bidirectional way (Casey and Savastinuk 2006; Crawford 2006).

In museums the user perspective is been typically more product-oriented (exhibition and collection) and focused on measuring user satisfaction with the available offerings (Booth 1998; Spiegel et al. 2006). Museums have, for some time, placed a significant emphasis on providing experiences and making exhibitions interactive, but the baseline is still that a museum has a predefined set of offerings and users can either take it or leave it.

In spite of the calls for more emphasis on education and communication during the last decade, user and use perspectives have received little attention in archives and records management operations, in comparison to, for instance, LIS (Kostiainen et al. 2003; Sundqvist 2007). Both the prevalent historicaltechnologist paradigm of archivistics and the more recent scientific-informational paradigm (Ribeiro 2001) have taken it as a premise that an archives is what it is and the role of users and user education is limited to learning and using the resources as they are (Ketelaar 1992; Cook 2001). The viewpoint can be traced to the notion of keeping an archives existing, and as such 'available', instead of considering use as a relation between archival materials, users, and usages. Only recently have some researchers taken a more in depth interest in users and especially the use of archival records (Duff 2002; Sexton et al. 2004b; Sundqvist 2007) and even more recently in engaging users (Yakel 2007; Shilton and Srinivasan 2008; ArchivesNext 2007; Raymond 2008).

The purpose of this article is to discuss communication and user participation in archival contexts. This study refers to two digital archives projects and the insights gained during the research and development work to formulate a new approach of a participatory archive to address and discuss some of the fundamental issues of user and usage orientation and participation in archives. These two projects concern historical archives and in both cases the principal relevance of the records is historical and cultural value. In spite of the historical nature of the case examples, the suggested ways of interacting with an archives 
are not specific to historical records. The fundamental characteristics of the proposed approach are decentralised curation, radical user orientation, and contextualisation of both records and the entire archival process.

\section{Archives and their users}

For a long time, an implicit assumption in archival science seems to have been that the people who come to an archives know what they want, are knowledgeable enough to be able to express their needs in archival terms, and even better, able to help themselves as much as possible both in practical matters and in analysing and interpreting the records. Traditionally, users have been expected to have a degree of expertise in the subject matter (mostly administration and in historical archives, in the relevant historical contexts) to be able to use the records. Archivists and archives have published manuals on particular topics, such as genealogy (Eales and Kvasnicka 2001) and diplomatics (Bruebach 2003), to help users understand records.

On the other hand, very little was done to make archives understand their users until the 1990's. During the last decade and there has been a growing empirical interest in users of archival materials both by academics and archival institutions (Moline 1994; Gilliland-Swetland 1998; Gilliland-Swetland et al. 1999; Duff 2002; Duff \& Johnson 2002; Toms and Duff 2002; Yakel 2000; Pick 2001; Yakel 2002; Yakel \& Torres 2003; Anderson 2004a; Duff 2004; Hill 2004; Sexton et al. 2004; Sexton et al. 2004b; Yakel 2005; Watkins 2006; Sundqvist 2007). However, in spite of the growing number of investigations, there has been little discussion on the theoretical underpinnings of the notions of user and especially of use (Sundqvist 2007). In practice, most of the efforts have focused on historians and their use of archives (Duff 2002; Duff \& Johnson 2002; Tibbo 2002; Toms \& Duff 2002; Duff 2004; Sundqvist 2007). Other user groups or even researchers of other scholarly disciplines have attracted considerably less attention. Gilliland and her colleagues $(1998 ; 1999)$ have studied archival records in elementary school contexts and, for instance, Yakel and Bost (1994) and Kostiainen et al. (2003) have worked with administrators. Even in these cases, the notion of use has had a rather record-centric character. The studies have focused on a record as it is and observed, how it is eventually found, by whom and whether it is retrieved for use or not. Studies like Shankar's (2004) ethnographic investigation of record keeping 
and Duff and Fox's (2006) work of reference archivists are rather rare examples of perusing use as a broader notion, which comprises several stakeholders, activities, and contexts rather than as a relatively abstract idea of 'users' searching and choosing records of their (rather abstract) interest. Projects like Developing Archival Metrics in College and University Archives and Special Collections (http://archivalmetrics.org) and the AX-SNet (http://www.axsnet.org/index.htm), the Archival eXcellence in Information Seeking Studies Network, represent a new line of interest in information seeking and use in archives context. Besides actual user studies, there have been several calls for rethinking users and technologies (Cox 1998), engaging users in building archival collections (Shilton and Srinivasan 2008), describing archival materials and for harnessing the potential of next generation of social finding aids (Duff 2002; Anderson 2004a; Yakel 2007; Anderson 2008). Recent examples of applying web 2.0 technologies to digital archive contexts in order to promote user input have been published by Yakel et al. (2007) and Shilton and Srinivasan (2008).

Even the descriptive user studies have undoubtedly served to solve many actual practical issues in archival institutions and have helped to develop better finding aids; but it doubtful whether they have succeeded or even attempted to scrutinize or question the fundamental notion of using an archives. Basic observation of user behaviour follows the line of the premodernist and modernist paradigms in archival science, which posited that archivists are expected to remain neutral, disinterested, and impartial mediators of archival material (Cook 2001). The approach is usable for 'neutrally' aligning services to the actual patterns of how users are using an archive. Theoretical reasoning is needed, however, as a basis for discussing whether the present patterns of use reflect the actual needs or desires of the users, or whether they make good use of the potential of archival materials.

Besides lacking theoretical depth, the historian-centric image of current and potential users of archives is rather narrow. Adams (2007) points out that in the United States there has been a change in the user base of the National Archives and Records Administration (NARA) during the last 30 years. Traditionally, the principal group of users has been researchers. Researchers, primarily with social science background, are still in the majority, but a significant portion of visitors are at the moment people looking for information instead of data. The relative 
proportion of non-researchers among users is expected to increase in the future (Menne-Haritz 2003), but also researchers, the traditional archive users, are beginning to place non-traditional demands on archives and their services (Lybeck 2003).

Adams (2007) asserts that the changes in user population relate to the growth of the types of records hosted by NARA, but also to the evolution of reference services in the electronic records section. The increase in the volume and the types of both records and services have their roots in the evolution of recordkeeping practices (Wareham, 2002; Bruebach, 2003). These changes have also pertained to changes in the ideas and infrastructures for managing and making archival material available during the last quarter of a century (Meijer 2001; Bailey 2007). 'Freie Provenienzprinzip' has already lifted the condition of strict pre-order provenance, which effectively contributed to the usability of archives and the findability of records (Bruebach 2003). Macro-appraisal methodology fosters a similar ideology in archival appraisal. Besides focusing on increasing the relevance of preserved records, the emphasis on activities and phenomena behind individual records has the potential of giving more explanatory power to an archives and increase its usability (Badgley and Meunier 2005). As an influential phenomenon, however, digitisation of information was instrumental in providing a means to search, access, and associate historical archival materials, regardless of the physical order and selection principles (Weinberger 2007). The computerisation of finding aids and especially the digitisation of archival materials have created new possibilities for reconsidering the notion of user orientation and for providing a multitude of entry points to the information. Simultaneously, the emergence of new recordkeeping practices and technologies for access and societal changes in many parts of the world from an essentially statist to individualistic stance has altered the public's expectations for memory organisations (archives, libraries and museums) (Mulrenin 2002). The new possibilities for access have been aligned with the general expectation of being able to access all information. Records and information are no longer as much state property as they used to be. Following the argument of Ketelaar (1992), archives and information are more of the people, by the people, and for the people than the people are for the archives. Menne-Haritz sees access more as a concept and an attitude, rather than as an actual use of archives. Access is about users 
making their own interpretations and respecting them. However, Menne-Haritz still sees archivists as neutral relayers, records as impartial pieces of evidence, and participation as something, which impedes the communicative process from the original event when a record was created to the event when it is being used at the present (Menne-Haritz 2001).

In a post-modern view, nothing in an archive or in the archival process can be neutral or even truly transparent (Cook 2001). Both archivists, archival records, and users represent a plethora of viewpoints, which all contribute to the formation of common and individual understanding of archives and archival materials. In the post-modern sense, the notion of participation is built into any human interaction with information, which makes it and its implications also essential in the archival and records management contexts.

\section{Digital archives at Saari Manor and Kajaani Castle}

This case study is based on two projects with the objective of constructing digital historical archives, providing a set of tools for maintaining and updating them, and nurturing communication and collaboration based on the archival assets. Saari is a manor house located in Mietoinen (swed. Mietois), located in southwestern Finland. The history of the manor dates back to two medieval manor houses, which were merged in the 16th century to form a new larger manor called Saari. Saari was held by several noble families until 1943. From 1957 to 2006, the site hosted the Finnish national research institute for agricultural research (MTT Agrifood Research Finland). In autumn 2006, the site was acquired by the Kone Foundation. This private foundation, provides funding for researchers in the humanities, social sciences, and environmental sciences and houses a residence for artists and scholars at the manor (Säätiö 2007).

The digital archive of Saari Manor consists of the records of the manor and a growing corpus of associated information. The physical archive comprises 61 archival units of records from 1729 to the present. The digital archive (http://saarenkartano.muuritutkimus.fi/index.php/Main_Page) comprises digital surrogates of the oldest records from the 18th century to 1943 (Kivistö 2007). The development of the Saari Manor Digital Archive began after an initial reorganisation of the physical archival collection. The oldest archival documents, totaling approximately 1900 items, were digitally photographed at a working level 
quality during the reorganisation process. The collection of digital photographs was intended to be used for research purposes, but not to function as a full surrogate for the physical materials. The author of the present article was contacted when the idea of publishing the archival material on the web emerged. After the acquisition of Saari, the Kone Foundation provided funding for research about the manor. The principal incentive for making the materials available on the web was to enhance accessibility to the collection and allow remote consultation of the materials. As a byproduct, the improved accessibility would increase interest in the manor as a subject of research. Another consideration was to use the web archive as a platform for storing and publishing other kinds of research material from the manor including, for instance, archaeological documentation from investigations conducted at the site.

The Kajaani Castle Digital Archive began essentially as a spinoff to the Saari project. The work was commissioned by the Department of Sites and Monuments of the Finnish National Board of Antiquities. The archive comprises a set of records, including documents, photographs, maps, plans and drawings associated with Kajaani Castle and space by space and room by room documentation of the castle itself. The castle, now in ruins, is located in a town of the same name in northeastern Finland. The castle was built during the early 17 th century. It served as a military post and residence until 1716, when it was demolished by Russian troops (Heikkinen 2004; Lehtonen 2004). The original records of the digital archive are geographically dispersed in a number of archives and collections in Finland and abroad. Thus, the purpose of the digital archive is to reunite the collection and make these scattered materials available in a single location on the web. In the Kajaani case the relevance of the archive relates not only to research and, to a more significant extent than in Saari, also to the management of the heritage site. The work on both projects is ongoing as the notion of a participatory archive has evolved and has been extended to yet another site in Finland.

\section{Methods and layout of the study}

The two case studies were conducted using action research (Greenwood and Levin 2000; Kemmis and McTaggart 2000) as a principal methodology of investigation. The starting point was to build a working archive with appropriate basic functionality from which to develop both the technical and content aspects 
together with the actual users of the archive. The first discussions with the researchers in Saari at the beginning of the project clearly indicated that the potential users of a digital archive found it very difficult to conceptualise the possible uses and benefits of building a digital archive. Therefore an agile action research based approach was chosen.

The work started at Saari in autumn 2007 with a requirements analysis based on unstructured interviews of two subject experts who represented the users of the archives. The analysis proceeded with the formulation of requirements, which were validated in meetings with the previously interviewed subject experts, and a group of potential and actual users of the archive $(n=15)$. After the initial assessment of requirements, the work proceeded with an analysis of the archival records. The theoretical framework for the study of materials was based on qualitative document analysis (Altheide 1996, 23). The document analysis was concluded by analyzing the initial layout of the archival material in the system and reviewing the guidelines for digitising materials, processing digitised documents, and instructions for users of the archive.

After the initial steps, the study proceeded with assessment, selection, and development of appropriate indexing and classification schemes. Then came the selection, deployment, and development of archival system. The development process was guided by frequent consultation with the experts. The authors took responsibility for the information architecture and the installation, maintenance, and development of the archival system, as well as for the digitalisation of the archival schema and description framework and the management of the adapted participatory concept of archival.

The development for the Kajaani project directly follow that of Saari. This work proceeded with collection of background data and information relevant to the new contextual (Kajaani Castle) specific requirements, which were integrated into the earlier findings. Thereafter, the project continued with another series of development and evaluation cycles, characteristic of iterative design projects.

\section{Requirements analysis}

The work on the digital archive began with an evaluation of the present and future needs for the archive. The principal informants were the historian and researcher, Terhi Kivistö, who was also responsible for organising the physical archival 
collection and archaeologist, Kari Uotila, who conducted archaeological research and survey of the manor site. The author's role was to conduct the requirements analysis, deploy an archival management system and to work with cultural heritage information management issues.

The central themes which appeared in the discussions were geographical dispersion of individual users, existence of multiple parallel viewpoints, interpretations of each information object, variety of the types of relevant information objects (ranging from manuscripts to physical objects and measurement data), and the fact that the expertise in different aspects of the information objects was held by different individuals. Even though the prospective number of active concurrent users of a relatively focused corpus of material was estimated to be relatively low, a potential for collaborative use of the system was conceivable. The collaborative nature of research was particularly underlined in the context of archaeological fieldwork (Huvila 2006). In a multiuser environment, the ease of use and the importance of minimising the possibility of accidental removal of records were considered necessary. From a technical point of view, the emphasis was placed on search facilities, ease of maintenance, and future portability of data.

The baseline discussions with the two subject experts established a general framework for developing the working concept of the digital archive which could be tested and developed further during the course of the research project. The principal findings of the interviews were:

1. Informants indicated clearly that individual researchers have expertise on different aspects of the documents and their contexts. These individuals may be expected to be interested in some documents but not to be skilled in archival information management.

2. Both informants thought that users would be encouraged to participate if there were no possibility of accidental removal of documents and metadata. On the other hand, it was considered to be impractical and too laborious to restrict access by trusted users to edit parts of the documents.

3. The types and formats of relevant documents (e.g. manuscripts, images, different types of measurement data) cannot be determined in advance. Especially in archaeology, documentation methods and 
techniques change rapidly and thus support for new document types is needed at regular intervals. (see also finding 6)

4. Even though the informants agreed with the benefits of standardised descriptions, they also underlined the need to be able to insert data and descriptions as they are. Conventions vary between different scientific disciplines and some preliminary and new observations may not be formal enough to fit in a standardised descriptor format. Similarly, it was agreed to be more important to capture as much relevant information as possible than to strictly enforce a formal descriptive scheme.

5. All interviewed experts agreed that users are likely to employ a variety of search strategies. The most important functions for the archive were considered to be findability and accessibility. The consensus was that the primary added value of a digital archive is to make the materials accessible on the Internet, which should not be compromised by the design of the archival system.

6. A central technical concern of the informants was whether everyone could access and use the archival materials without specialised software. Both of the principal informants were willing to install additional software for access to the archive only in special cases.

7. The budget of the project was limited. The central stakeholders also lacked advanced computing expertise and full-time personnel for technical maintenance of the digital archive system.

The central findings of these interviews could be explicated to a set of corresponding (see numbers) requirements:

1. Multiuser browsing, editing, and maintenance. Even though the archives needs to have a responsible technical editor for the maintenance of the general information architecture and the consistency of the archives, the majority of the use, editing, and maintenance work will be done by individual researchers and research groups working at the site and having the highest subject expertise on the materials.

2. Versions and tracking of changes on the level of individual contributors. Due to the collaborative nature of the use of the archival 
materials, every trusted contributor needs to be able to edit all content of the archival materials. However, for the same reason a comprehensive roll-back facility is needed to prevent accidental removal of content. Similarly, in spite of the necessary policy rules to ensure adequate documentation of any changes and claims, it is beneficial that all changes are also documented automatically and attributed to named users.

3. Flexibility of data and structure. Due to the requirement to be able to contribute basically any kind of material to the archive, the templates for different data types need to be flexible enough to accommodate a broad variety of documents and file formats.

4. Flexibility of description. Due to the variety of materials and the collaborative and multidisciplinary nature of the use of the archives, archival descriptions need to allow for extended flexibility. Not all standard archival metadata is necessarily known on a document level as there is little earlier research on the documents. It is essential that the missing data can be input gradually during future research projects, and that description is not a one-off effort. The collaborativeness and multidisciplinarity of research is likely to reveal very diverse needs for description and, for instance, links between records representing a variety of different relationships. These are difficult to integrate into a static data structures.

5. Searchability and formalization of descriptions. In spite of the requirement for flexibility, to be able to conduct exhaustive retrieval of archival data, there is a need for a degree of standardisation or formalization and commensurability of the archival metadata and descriptions attached to the records.

6. Standard file formats. According to general practises and principles of archiving (Thomassen 2001) all the materials should be preserved in standard file formats, which last and retain their usability and accessibility also in the future. From the end-user point of view, the materials need to be accessible (as far as possible) with standard client software (of any given period) without the need to install additional software components. 
7. Standard, inexpensive, and easily transferrable software. The considerations for file formats also apply to the digital archive software itself. The software should be based on a solid, regularly updated and supported code base with a long expected life-cycle. The prospects of return on investment (ROI) are limited, which set a preference for inexpensive (both investment and total cost of ownership (TCO)) alternatives. Similarly, due to the expected lack of technical and financial means for maintaining a dedicated server, the software should function in a relatively standard and basic server environment to allow greater freedom of choice in server operators and easy transfers from one service provider to another in the near foreseeable future. In the longer term, the contents of the archive need to be exportable from the present system in a consistent format, which can be parsed and read into a new system.

On the basis of the initial framing of rationale for creating a digital archive and an analysis of requirements, the work proceeded by evaluating digital library systems. Funding and maintenance considerations led the evaluation to focus on open source software. The limited prospects of ROI and the need to rely on a publicly available and documented systems limited the consideration of any commercial alternatives. For the same reason, a decision to build a dedicated system was abandoned.

The evaluation effort focused on large scale digital archiving and information storage software. The two main types of software were analyzed: digital library systems and wikis. The systems evaluated were: Fedora Digital Library, CDSWare, JeromeDL, E-Prints, DSpace, Greenstone, Keystone, BRICKS Framework, Kete, and dLibra digital library frameworks and Platypus, Mediawiki with and without the Semantic Mediawiki extension and TWiki wiki. After a preliminary survey of the available alternatives, the requirements were rewritten in more specific terms as explicated in Table 1.

Table 1: Functional and technical software requirements for the digital archive

\begin{tabular}{|l|l|}
\hline Functional requirement & Specification \\
\hline $\begin{array}{l}\text { Multiuser browsing, editing and } \\
\text { maintenance }\end{array}$ & $\begin{array}{l}\text { Unlimited number of user } \\
\text { accounts with three levels of } \\
\text { rights: administrator, contributor } \\
(\mathrm{read} / \mathrm{write}) \text { and guest (read). }\end{array}$ \\
\hline
\end{tabular}




\begin{tabular}{|c|c|}
\hline & $\begin{array}{l}\text { Tools for collaborative } \\
\text { coordination of the } \\
\text { maintenance. }\end{array}$ \\
\hline $\begin{array}{l}\text { Versions and tracking of changes on the } \\
\text { level of individual contributors }\end{array}$ & $\begin{array}{l}\text { - Version tracking } \\
\text { - Cumulative edit history } \\
\text { (unlimited levels) } \\
\text { - Records of all edits and their } \\
\text { authors }\end{array}$ \\
\hline Flexibility of data and structure & $\begin{array}{l}\text { Users with contributor rights } \\
\text { can easily create new record } \\
\text { types (including e.g. images and } \\
\text { archaeological data) and add } \\
\text { necessary data fields (and data) } \\
\text { to existing records. }\end{array}$ \\
\hline Flexibility of description & $\begin{array}{l}\text { - All records can be described } \\
\text { how the different users consider } \\
\text { it as applicable using formal } \\
\text { descriptions, free text, diagrams, } \\
\text { pictures etc. } \\
\text { - Template system (or similar) to } \\
\text { guide users to contribute as } \\
\text { uniform descriptions as } \\
\text { possible. }\end{array}$ \\
\hline $\begin{array}{l}\text { Searchability and formalization of } \\
\text { descriptions }\end{array}$ & $\begin{array}{l}\text { - Formal descriptor and data field } \\
\text { based searching facility (e.g. for } \\
\text { specific authors on author field, } \\
\text { keywords on keyword field). } \\
\text { - } \quad \begin{array}{l}\text { Possibility to search for ranges } \\
\text { of numeric values and e.g. dates }\end{array} \\
\text { - Full-text search facility }\end{array}$ \\
\hline Standard file formats & $\begin{array}{l}\text { The archive needs to be usable } \\
\text { (read/write) using a common } \\
\text { web browser (Internet Explorer, } \\
\text { Firefox, Safari) without } \\
\text { additional plugins. } \\
\text { - If needed, publicly available and } \\
\text { supported client-side plugins } \\
\text { may be considered for } \\
\text { presenting alternative content. }\end{array}$ \\
\hline $\begin{array}{l}\text { Standard, inexpensive and easily } \\
\text { transferrable software }\end{array}$ & $\begin{array}{l}\text { Documented e.g. XML-based } \\
\text { machine readable export of all } \\
\text { contents of the archive. }\end{array}$ \\
\hline
\end{tabular}




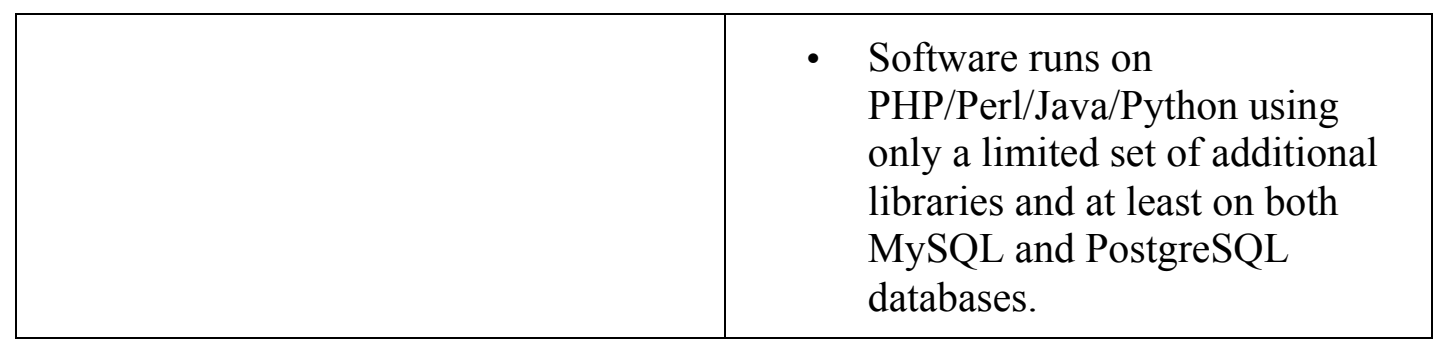

The principal issues can be categorised into five areas: 1) technical, 2) documentation, 3) archival functions, 4) support and 5) usage related.

1. Technical: many software packages required extensive customisation of the server environment, a large number of specific libraries required a specific backend database system.

2. Documentation: a number of functionally adequate systems were extremely poorly documented and thus evaluated to be too risky and problematic to deploy and maintain.

3. Archival functions: a number of digital library related software packages were designed to house a collection of books or other published digital material. The systems did not accommodate storing archival records or archaeological data. Another set of problems was related to the limited possibility of linking records to each other and describing links in a semantically rich manner. Version management and edition history was lacking in most of the systems. In wiki systems the most significant archival functions related problem was the unstructured nature of the records and the resulting difficulty of maintaining the integrity of an archive.

4. Support: a number of packages were developed by small communities or individual institutions with a small base of installations. Adapting a relatively infrequently used software was considered to be too risky from the support and maintenance point of view.

5. Usage: Most digital library systems were based on a workflow model where a digital object is submitted to the system and an editor either approves or denies its publication (e.g. DSpace workflow in Branschofsky and Glavash 2003). Collaborative features were lacking in most of the systems.

On the basis of the assessment of available software, the conclusion was that there is no perfect system around for the projects. It became clear, however, that the 
various requirements were met at a fully satisfactory level by a wiki and more specifically, by a semantic wiki. The chosen technical platform was Mediawiki software complemented with the Semantic Mediawiki extension (Krötzsch et al. 2005). The platform provided a flexible, but still a semantically unambiguous means for organising, preserving, and describing digitised archival assets. Other semantic wikis were considered, but the majority tended to be in relatively early stages of development and all of them were less attractive in comparison to Semantic Mediawiki in terms of its stage of development, relative simplicity of maintenance, size of developer and user community, support for different kinds of media, and availability of extensions (Kotelnikov et al. 2007; Tazzoli, Castagna, and Campanini 2004). In addition to the flexible facilities for information storage, the (Semantic) Mediawiki provides tools for collaboration, which are mostly lacking in the digital library systems. Another possibility would have been to link a digital library platform to a wiki (as in http://files.eprints.org/), but this would have not removed the issues related to the linearity of record publication process and would have necessitated additional work of integrating the two systems together. Furthermore, the integration would not have been seamless from the user point of view.

\section{From a digital archive to a participatory archive}

In order to meet the flexibility and collaboration needs explicated during the requirements analysis for both projects, the digital archives were designed to be based on a system of semantically typed, described, and interrelated records. One record (a page in wiki terminology) may represent a single actual physical (stored outside the digital archive) or digital (stored inside the archive) archival document. Thus, a record (wikipage) can be a resource or a description about a record (cf. Kotelnikov et al. 2007). Each document is supposed to have one or several types including technical types of Semantic Mediawiki system (such as Page, String, Number, or Date, see Semantic Mediawiki 2007), internal types used to distinguish several archival and functional categories of records (e.g. different archival entities, types or documents, example records, keywords and digital reconstructions) and types based on CIDOC-CRM classes, e.g. "E31 Document" for documents and "E38 Image" for images (Crofts et al. 2007). Besides the typing, relationships between different documents are expressed by using CIDOC- 
CRM Properties (e.g. Crofts et al. 2007), and when needed, by using other, preferably standardized, types of semantic linking.

In order to strengthen the theoretical basis of the two digital archives, we adopted an approach based on participation in archives and records management. Apart from the present study and the findings of the requirements analysis and the action research, the primary foundations of this theory is in the user studies paradigm of archival science and LIS (discussed earlier), participatory libraries and conversation theory (Lankes, Silverstein, and Nicholson 2007a; Lankes et al. 2007b), participatory information systems design (Schuler and Namioka 1993; Kensing and Blomberg 1998; Bodker, Kensing, and Simonsen 2004) and the intriguing proposals on the so-called wisdom of the crowds (Surowiecki 2004), the Long Tail (Anderson 2006), social physics and critical mass (Ball 2004) and the miscellaneity of everything discussed by Weinberger (2007). In a sense, the participatory approach could be denoted 'archive 2.0 ', but we argue that the notion 'participatory' better captures the pertinent aspects of the proposal than the notion of a 'second full version' or '2.0'.

The proposed participatory approach to archival management envisions a digital archive essentially as a self-steering system like a crowd (Surowiecki 2004; Ball 2004) and places a special emphasis on the collaborativeness and conversationality of archive building (in similar fashion to Lankes et al. 2007b; Suchman 1993). The coherence of a repository is maintained by a set of minimum requirements for new entries. Otherwise the system relies on total findability provided by user indexing and full text search (Weinberger 2007). In practice, an information manager or a group of managers (depending on their role, possibly elected among the participants or nominated by the hosting institution) are needed to supervise the system, but the role of the managers is technical maintenance rather than appraisal and value judgments or proactive facilitation (Shilton and Srinivasan 2008). As already noted in the earlier discussion on the literature on archive users, none of the participants, the person who created a record, an information manager, or a contributor, can be expected to be neutral. Unlike in the access paradigm of Menne-Haritz (2001), a participatory archive pursues transparency through participation and not its opposite. Inclusion and greater participation is supposed to reveal a diversity of motivations, viewpoints, 
arguments and counterarguments, which becomes transparency when a critical mass is attained.

The focus of a participatory archive is in its emphasis on the issues explicated in the requirements analyses of the two projects, which are lacking support in the traditional non-participatory archival paradigm. The fundamental characteristics of the proposed approach are

1. Decentralised curation: The curatorial responsibilities are shared between archivists (or information managers) and the participants in an archive, who as a collective have the most indepth subject knowledge on the records, their contexts and uses.

2. Radical user orientation: In the traditional archival paradigm the first issue has been preservation and the archival process. Usability of the archive has generally been of lesser importance until recently (Hill 2004; Sexton et al. 2004). In a participatory archive the usability and findability of the resources is the number one priority. This then guides the practises of preservation and appraisal (not compromising them). In a participatory archive the usability does not denote use alone, but also a deeper level of involvement in the sense of actual participation in the archive and in the archival process. Radical user orientation means that the archive is oriented and reoriented to its users all the time.

3. Contextualisation of both records and the entire archival process: Archives have placed a strong emphasis on contexts in the sense of the principle of provenance and the contexts of the records (Cunningham 2007). Besides the traditional record and archive-centred contexts (an archive as the context of a record), a participatory archive also acknowledges the importance of other than archival and organisational contexts of records, such as those of their originators, curators and users.

Yakel, Shaw, and Reynolds (2007) discuss a project of creating a digitised version of the archives of the Polar Bear Expedition. The expedition, by its official name “American Intervention to Northern Russia, 1918-1919”, was a U.S. military 
expedition to Northern Russia in the end of the World War I. The digital archive was a joint project between the Bentley Library and School of Information at the University of Michigan. The focus of the research project related to the archive building was on developing a new generation of archival findings aids. The digital archive system, built on the Everything2 software (http://www.everything2.com/), incorporates several participatory navigation features based on commenting, collaborative filtering, bookmarking, and visitor awareness. The findings aids used in the Polar Bear archive are also relevant in the context of the participatory archive. Most of the concepts are supported in some manner by the MediaWiki software used in the present study. The concept of wikis and Everything2 do, however, differ in some aspects, which makes direct comparisons difficult. User tracking and awareness in Mediawiki is based on following changes and contributions rather than browsing and the movement throughout a site. The proposed model of participatory archive shares its basic approach with the participatory archiving model of Shilton and Srinivasan (Shilton and Srinivasan 2008). The baseline for both of these approaches is in engaging users, as opposed to archivists, in archival tasks. The participatory archiving model and participatory archive differ, however, in several aspects. Shilton and Srinivasan discuss participation in the context of building a community information system for the South Asian population in Los Angeles. According to the participatory archiving model the South Asian community members will be asked to "create, upload, and share documentation of their heritage and identity" (Shilton and Srinivasan 2008, 98). The first difference in the approaches is that Shilton and Srinivasan seem to discuss essentially building, appraisal, provenance, ordering and description of an archival collection, and participatory development of archival ontologies instead of working with an archive as an evolving corpus of process-bound information with self-emerging ontologies. The second major difference is that in the participatory archiving model, communities are an actor, and the archive will be based on a consensual community ontology of the participating community members set within a theoretical framework based on archival science. In a participatory archive, there is no predetermined consensual community. The 'community' is a sum of all individual structures, descriptions, orders, and viewpoints contributed by individual participating archive users whether they are users or contributors, archivists, researchers, administrators, 
labourers, or belong to marginalised communities or the majority. The proposed role for information managers is to maintain the technical platform, provide adequate tools for working with the archive and to provide a minimum technical level of findability of individual records. Otherwise than from the technical point of view, information managers are equal to the other users of the archive. Their role is not to direct the process of how an archive emerges, how something is described, appraised or what provenances relate to the materials. Following McKemmish et al. there are an infinite number of possible parallel provenances (McKemmish 2005a), descriptions, orders, and pathways to the archival information. Participatory archive assumes no consensus on order, no first order of order (Weinberger, 2007, 17-19), just the necessity of keeping information findable.

***Anderson (2008) has called an online archive service, which incorporates web 2.0 elements as Interactive User Community or type 6 web service in the The Model for Archive Web Development (MAWD). A participatory archive belongs to this category, although from Anderson's point of view approaches such as those of Yakel, Shaw, and Reynoleds (2007) and Shinton and Srinivasan (2008), focus on creating participation around instead of within an archive. Their principal difference to the participatory archive approach is that they retain the $a$ priori authority for archivists and focus on participatory information seeking rather than participatory management of the archive. Users are invited to comment on resources, but changes to the records are made by archivists. The motivations for adopting a post-controlled approach and emphasising radical user orientation in a participatory archive by allowing the users to edit actual records is to capture richer descriptions and links between records, to accelerate the process of updating the archive, to engage users to collaborate actively within the archive, and to reduce the need for administrative interventions. The radical user orientation is based on an understanding that together the participants are more knowledgeable about the archival materials than an archivist alone can be. Therefore, the participants should have the first access to an archive and the archivists and information managers only a subsequent one. It is assumed that the participants could be trusted enough to allow them to make changes in the records. The versioning facility of MediaWiki software also makes restoring files much easier and quicker. Besides the possibility of editing records, the users' 
were also given the ability to comment on resources using separate discussion pages related to the records or to contact information managers with their suggestions to make contributing as easy and as comfortable as possible. In the sense of harnessing the knowledge of the audience, the concept of participatory archive is also similar to that of Footnote.com. The service collects digitised versions of old records and allows users to comment and tag them with their observations (www.footnote.com). Even though a participatory archive is about crowdsourcing, it focuses on deeper involvement and more complex semantics rather than on larger crowds and simple annotations. The participatory archive is about digital participation and the present projects used a technology commonly placed under the umbrella of Web 2.0. The central underpinning of decentralised curation, radical user orientation, and broader contextualisation of records management is a digital form of information. A participatory archive is not, however, as such about Web 2.0 technology and not necessarily all Web 2.0 supports these four characteristics of a participatory archive. The present study does not suggest that the chosen technology platform would be ideal for the discussed purposes, but in essence a wiki differs from many other Web 2.0 technologies through its basic philosophy of participation. Blogs and podcasts can be used to make an archive and archival work more transparent, to orient them towards users, and to contextualise documents as in The Smoking gun (http://www.thesmokinggun.com/) or in Strange Maps (http://strangemaps.wordpress.com/). Folksonomies and commenting tools can form part of the decentralised curation of archival descriptions. Social communities can be used to gather interested people together. From an archival point of view, the mentioned Web 2.0 technologies, however, are situated unlike wikis at the interface between archival materials and their users. This limits participation to a conversation about a record instead of using a record and its description as a conversation and an arena for participation.

In spite of the radical orientation towards users and contributing to an archive, a participatory archive does not attempt to trivialise the role of archivists or the importance of archival work. A participatory archive focuses on user orientation, participation and broad contexts, but an important aspect is that it subscribes to the elementary archival requirements. A participatory archive is not a complementary layer, but a primary knowledge repository about records and their 
contexts and an archive instead of a digital library (Cunningham 2007). In terms of the mandatory OAIS responsibilities of an open archival system (for Space Data Systems CCSDS, 3-1), a participatory archive does:

1. Negotiate for and accept appropriate information from information producers.

2. Obtain sufficient control of the information provided to the level needed to ensure long-term preservation.

3. Determine, either by itself or in conjunction with other parties, which communities should become the designated community and, therefore, should be able to understand the information provided.

4. Ensure that the information to be preserved is independently understandable to the designated community. In other words, the community should be able to understand the information without needing the assistance of the experts who produced the information.

5. Follow documented policies and procedures which ensure that the information is preserved against all reasonable contingencies, and which enable the information to be disseminated as authenticated copies of the original, or as traceable to the original.

6. Make the preserved information available to the designated community.

As a social participatory system, the responsibilities are largely controlled by the contributors and users of the archive together through their contributions and discussions. The first emphasis of a participatory archive is to make the preserved information available and understandable to the designated community (i.e. those who should be able to understand the information provided) (Consultative Committee for Space Data Systems CCSDS, 1-1) (responsibility 4 and 6). The participatory archive is by itself an open designated community (responsibility 3 ). All individual members of this participatory community have a responsibility to provide enough contextual information on records and their descriptions so that the content is independently understandable to their peers and not only for themselves. According to the general directions of use, all participants of an 
archive are required to follow the documented guidelines to ensure that the information is preserved against all reasonable contingencies, and kept traceable to the original information within the archive (responsibility 5). The platform itself keeps record so that all information is traceable to its contributor, which can be used in the short term as a complementary source of contextual information. In the long term, all personal communications and clarifications would be added to the archival description. The participatory notion does not assume that information is self-sufficient outside its archival context, but the necessary contextual information needs to be available and detachable from the archive if needed. At the moment, the information is available both in XML and RDF formats and can be harvested by using OAI-PMH protocol. Using the OAI-PMH harvesting functionality, the archives can be linked to other archives, made searchable in archive portals and linked to larger e-Science infrastructures (e.g. DRIVER Project 2007).

The remaining criteria are based on the availability of information and the consequent possibility of participating in forming, enforcing, and implementing the responsibilities. A lowest common denominator approach was adopted to ensure that all objects deposited in the repository are always findable using some standard set of indices and that the minimum metadata would not be too complicated and burdensome to input from the point of view of an individual user who is likely to be interested in the contents of the archive rather than indexing. The lowest common denominator approach we adopted is essentially a compromise of descriptions and economy of work. The multiple search facilities and participatory indexing can provide enough additional pointers to the information in the long run to add value to the repository and compensate for the limitations posed by minimal metadata.

The Saari and Kajaani archives use the Dublin Core 1.1. (Initiative 2003) specification as the minimum set of descriptors. All descriptors are expressed as semantic relations in form of "[[DescriptorName::Description]]" (Krötzsch et al. 2005). The policy for archival descriptions and preservation metadata follows the EAD standard (EAD Working Group 2002). The users are encouraged to use CIDOC-CRM (Crofts et al. 2007) as the principal model for describing the semantics between individual information objects; however, the precise choice of descriptive semantics is left to their discretion. Inclusion of additional semantics is 
encouraged whenever appropriate. The standards are implemented by tagging documents with semantic relations, which correspond with individual descriptors. Standard compliant XML-files such as EAD findings aids may be generated from the RDF output of the semantic tags. As Cunningham (2007) underlines, a digital archive is not a digital library. Therefore, the users are reminded about the need to focus on relational semantics: a participatory digital archive is not about individual digital information objects, but about an entire archive. All records belong to the process of their origin and in addition to their contexts of use, they have to be described as a part of their current and original archival contexts. The OAIS responsibility of negotiating for and accepting appropriate information from information producers is managed by a policy of accepting any information approved by the participants, which can be linked to the archive, its topic (e.g. Saari manor, Kajaani castle) and to the already existing records in a meaningful way (responsibility 1).

Even though the majority of responsibilities fall on the participatory archive as a social system, the organisation which hosts the archive plays a central role in facilitating the preservation and functioning of the archive. The technical and organizational issues of hosting the archival system have to be managed on a permanent or, in practice, in reasonably long-term basis. Similarly, the host must have sufficient privileges to keep the materials online permanently and to migrate or process them in any manner which is relevant to their continuing usability and preservation (responsibility 2). In order to meet the basic archival preservation and management criteria, the projects took specific steps to consider and follow the CALIMERA (http://cordis.europa.eu/ist/digicult/calimera.htm ) digital preservation guidelines. The specific emphasis of our efforts was on the usability of the preserved resources, therefore our approach maximises the use of these resources on a long-term basis and only secondarily that the resources are available 'permanently'.

In general, the Mediawiki with Semantic Mediawiki system (Krötzsch et al. 2005) extension supports the basic requirements of an open digital archive well. The system provides a mechanism by which to attach a set of formal semantic properties and types to individual documents and it provides a relatively good set of tools for the management of an archive and archival process. Due to the specialist nature of the materials in both the archives, access to edit the archives is 
granted upon request. A complete open access would be another, and in principle a preferred, possibility, which might help to gather more relevant input. On the basis of the requirements analysis, the long-time ratio of relevant and irrelevant contributions of non-registered users was estimated to be too low to motivate an increase in the work of removing unwanted modifications. The judgment was based on the low number of Finnish-speaking active researchers working on Finnish manor houses and related topics and a total estimate of possible irrelevant contributors. The total number of users is followed by using log files and if the traffic seems to grow significantly, the policy can be changed. In case of archives with more generally interesting materials, a feasible alternative would be establishing a test period. The MediaWiki software used in the two projects offers well-designed tools for monitoring edits and user activity, which makes it easy to follow participation patterns and to change policy at short notice.

\section{Discussion}

The research and development process raised several issues, which required immediate attention and were solved during the action research process. Some of the issues called for a deeper discussion and were used in formulating the theoretical proposal. In spite of the specific emphasis on usability and collaboration, another central concern in a participatory archive as with any archive, is how to manage the archival processes and preserve records for operations management, accountability and cultural-historical purposes (Thomassen 2001). In the following section, the discussion is focused on the specific aspects of participation and its functioning in an archive, sustainability of a participatory repository, its trustworthiness and technology-related issues.

The fundamental difference of the notion of the proposed participatory archive is in the notions decentralised curation, radical user orientation and in a both broader and deeper contextualisation of records and the entire archival process. The Polar Bear Expedition Archive discussed by Yakel, Shaw, and Reynolds (2007) orients towards its users and contextualisation of archival records by implementing social navigation and commenting facilities. Interaction is, however, separated from the actual archival records and is filtered by archivists making it less 'radical' than in the participatory archive and extending contextualisation only to the archival 
records. The participatory archiving model of Shilton and Srinivasan (2008) on the other hand focuses on rethinking the archival process and involving the communities where records originate. The model suggests taking the discussion of appraisal, arrangement, description and provenance to a community level. The post-coordinated approach of the participatory archive differs from this proposition by letting contributors and users to curate and to decide of the forms and frameworks of participation. The approach also decentralises curation to the participants who both contribute to and use the archive. It also allows communities and contexts to take form within the archive instead of assuming a community as a precoordinated entity.

Technically, the two archives discussed in this article make no assumptions as to what is being stored in the repository and whether it is uniform or not. The difference from a digital library is in the focus on the contexts of the material rather than on individual information objects (Cunningham 2007). By the openness of the approach, Portico Electronic Archiving Service (Ithaka Harbors 2007) represents a similar effort on joint availability of scholarly literature. While Portico builds a central repository, the DRIVER project (DRIVER Project 2007) aims at developing a framework for a European wide e-Science infrastructure and interoperability of archival access to different European archives. The participatory archive does not aim at forming a central repository or even an infrastructure, but at plugging into the already existing ones. In comparison to institutional repositories and digital libraries, the curation effort is decentralised even if an individual archival system and archival information is hosted by one organisation. Radical user orientation in the context of the participatory archive means that the archive is reoriented to its users all the time. In a typical user oriented approach, the system and archive would be built in cooperation with a group of users. The radical user orientation assumes that the moment when an archive is built is the starting point for participation. Because it is impossible to engage all prospective users in a design and building phase, a participatory archive is built quickly on the basis of a working specification and the actual development begins only when the system is in operation.

The most essential question regarding a participatory archive is whether it works or not: whether the users contribute to an archive and whether the contributions create added value. According to the earlier studies on collaborative digital 
information repositories, the functional sustainability of a repository is highly dependent on the activity of archive users and the emergence of a culture of collaboration, integration into daily practises, and a critical mass to sustain necessary level of contributions, which obliges others to contribute (Peddibhotla and Subramani 2007; Hollingshead Fulk, and Monge 2002; Dingsøyr and Røyrvik 2003). On the other hand, we suggest that the archive does not need to be updated constantly if its materials are of sufficient significance to some of the users. In the two cases discussed in the present article, the participation is likely to be occasional due to the specificity of the materials. For the same reason we do, however, expect that the specificity may actually induce deep collaboration between individual researchers similar to the notion of extreme collaboration (Mark 2002). In both cases there are potential participants who can actually benefit from remotely accessing the archive and who use the materials in collaboration. The future will, show how the actual usage develops and whether the present platform allows radical enough reconfigurations for the needs of the participants.

One aspect of the functional sustainability is how well the information infrastructure lasts and whether the logical and physical structure of the archive stays valid and maintains its coherence and consistence in spite of the fluctuations of users, uses and ways of conceptualising the repository and its contents. Because the third requirement for the system presumes that the types of the records may not be foreseen, to maintain a coherent structure of the archive, a minimum common denominator approach was adopted for the indexing and classification schemes. The users were encouraged to provide as much relevant archival metadata as they could (i.e. were motivated to invest time in indexing), but providing a basic Dublin Core metadata together with a relatively small technical classification was set as a definite minimum requirement for data entry. It is clear that the Dublin Core is by no means an ideal set of metadata for describing many of the records, but due to its relative prevalence, it was a practical choice. In order to increase the findability of archival documents a further emphasis was placed on asking users to index and describe records from a searching point of view (asking how they searched for a particular record) and on reusing existing descriptors as far as possible. 
Besides the structural and functional sustainability of the repository, another major issue relates to its trustworthiness. Besides the multiple technical issues in electronic records (Meijer 2001, 2003), user participation in the archival process causes new organisational and social challenges. Organisational trustworthiness is dependent on the members of the archive, but also on its host. Even if the participants are engaged in practices of appraisal, procurement, indexing and classification of archival content, the participation relies on a functioning technical and organisational infrastructure, which provides and hosts the archival platform and is likely to be the organisation, which employs an information manager or a group of them to perform the basic maintenance tasks (for the tasks see OCLC and CRL 2007).

Besides the trustworthiness of the repository and its context, the trustworthiness of individual records is of equal importance. As a collaborative effort, which relies on collective control, in a participatory archive there is always a question of the reliability of descriptions. In individual cases the reliability is highly dependent on the professional and scholarly authority of initial contributors of records and descriptions, and on the subsequent discussion of them and their validity. As in other collaborative knowledge repositories (McGuinness et al. 2006; Luyt et al. 2008), when it comes to the entire archive, its trustworthiness can be considerably less dependent on an individual authority or an authority of an individual academic group or viewpoint than in a traditional archive, which is a collection of static documents created by individuals and groups. A participatory archive represents a wider variety of interpretations and viewpoints and can follow more flexibly new directions of research and adapt to novel findings and research results.

From the technological point of view, I do not suggest that the chosen technology platform would be the definitive one for a participatory archive. Of the existing systems, however, a semantic wiki based approach was closest to meeting all of the original criteria. The already mentioned possibility of integrating a digital library system and a wiki or a discussion forum were not considered to be feasible options in the present cases. The workflow related issues would have remained the same, integration of two distinct systems would have required additional work and even then the fact of working with two different systems with distinct logic would have remained. There are some functions which could improve the 
usability of the present configurations in archival use. The search interfaces are not especially end-user friendly, there are no pages for missing type or property declarations or instantly available authority files at the editor interface. The recently released (version 1.0 on February 1, 2008) Halo extension (2007) to Semantic Mediawiki, which provides a graphical user interface to semantics, automatisation of some basic maintenance tasks, such as tracking of types and vocabularies and automated analysis and monitoring of the semantic structure is a definite improvement on the current systems discussed in this article. From a technological point of view, a list of further topics of forthcoming research and development include considerations for integrating the archival system with document management software, developing the records management process, and more extensive and long term user and usage studies. The NEPOMUK report on Interactive Semantic Wikis (Kotelnikov et al. 2007) contains interesting further proposals on developing the linguistic features of semantic wikis, which would undoubtedly contribute to the effectiveness and functionality of participatory archives based on the concept.

From the archival point of view, a central issue in a participatory archive is that meeting preservation responsibilities of an archival system is a less technical and procedural notion than in a closed professionally curated archive. The present software systems fulfill most of the technical requirements listed in the OCLC/CRL criteria of trusted digital repositories (OCLC and CRL 2007) or turns some of the traditionally technical criteria to social criteria (e.g. the handling of duplicates). There is certainly a need to understand the emerging new information work procedures in participatory archives and therefore the precise preservation requirements need to be reassessed and adjusted for this particular kind of information infrastructure. The principal advantage and problem foreseen with the wiki-based approaches is their emphasis on social rather than system-driven control (Ebersbach and Glaser 2004). Without adequate measures taken, decentralised curation and emphasised role of social control can be expected to cause other problems, such as lack of coherence and stability, but similarly this promises to solve some of the problems related to the inflexibility and rigidity of systems-based control of information organisation. 


\section{Conclusions}

The purpose of this article was to discuss a concept of participatory archive formulated and developed during two projects aiming at developing digital archives for two Finnish cultural heritage sites, the Saari Manor and Kajaani Castle. The premise of the participatory archive was developing and testing a concept as to how an archive could be radically aligned towards integration of and interaction with its actual and potential users and uses. The study was based on action research and conducted by the author. The materials stored in the two archives are historical by their nature and comprise a heterogeneous collection of documents, object drawings and other materials. Technically, the archival systems were based on Mediawiki software and its Semantic Mediawiki extension, which were considered to be superior to the available digital library systems when it comes to the key aspects of the formulated concept of the participatory archive: decentralised curation, radical user orientation and contextualisation of both records and the entire archival process. The ongoing projects use action research as a principal method of investigation. The baseline of the developing process is to build a working archival system according to a set of warranted requirements at the earliest possible stage and to proceed with iterations of continuous use, development and evaluation with the aim of nurturing participation and evolving the archive.

The notion of decentralised curation refers to harnessing knowledgeable users of archival collections to contribute in the form of new and improved descriptions, translations, summaries, and relationships to other records. Radical user orientation means following the principle of post modern archival science that the foremost functionality of an archival system is to make the contents of an archive available (Fredriksson 2003; Cook and Schwartz 2002; Cook 2001). Whether the radical user orientation actually generates participation depends on multiple factors. In the present two cases, participation can be expected to emerge as the groups of people who need and use the archive on a regular basis discover the sties. Development of actual usage and capabilities of the present platform can be judged only after a longer period of running the archives.

Other key aspects of curation, such as coherence and preservation are not compromised according to this view and they do not hinder use of records. The third notion of contextualisation refers to making an explicit attempt to capture a 
wider context of archival material beyond its provenance. From the usage point of view, whether it is for operations management, accountability, or historical research, equally important contexts can be found between archival hierarchies and in the formation of an archive.

The principal implication of assuming the notion of a participatory archive is the reconfiguration of responsibilities between curators, users and the general public. As the number of participants and the number of voices increases in the records management process, this broadens the relevant context of the records. Users themselves can point out the significant properties of digital objects (identified as one of the significant areas of future research in the Digital Preservation Europe Research Roadmap, in Hagen 2007) and use this information to steer the strategies and tactics of digital preservation further on. From the records management perspective, decentralisation and radical user orientation makes it possible to harness the Long Tail of archives by allowing existing and potential users to cooperate and contribute to the curation of digital repositories.

\section{Acknowledgements}

The author would like to thank Terhi Kivistö and Dr. Kari Uotila for cooperation and two anonymous reviewers for their invaluable comments on the earlier version of this paper. The study was financed by the Kone Foundation.

\section{References}

Adams M (2007) Analyzing archives and finding facts: use and users of digital data records. Archival Science 7(1):21-36.

Altheide DL (1996) Qualitative Media Analysis. Sage

Anderson C (2006) The Long Tail: Why the Future of Business is Selling Less or More. Hyperion, New York

Anderson, C (2004) The Long Tail. Wired 12(10):170-177.

Anderson, IG (2004) Are You Being Served? Historians and the Search for Primary Sources. Archivaria 58:81-129. (Anderson 2004a) 
Anderson, IG (2008) Necessary but Not Sufficient: Modelling Online Archive Development in the UK. D-Lib Magazine 14(1/2).

ArchivesNext (2007). An Archivists 2.0 Manifesto? ArchivesNext Blog $2007 / 08 / 20$.

Badgley K, Meunier C (2005) Macroappraisal, the next frontier: An approach for appraising large and complex government institutions. Archival Science $5(2): 261-283$

Bailey S (2007) Taking the road less travelled by: The future of the archive and records management profession in the digital age. Journal of the Society of Archivists 28(2):117-124

Ball P (2004) Critical Mass: How One Thing Leads to Another. Farrar, Straus and Giroux, New York

Bodker K, Kensing F, Simonsen J (2004) Participatory It Design: Designing for Business and Workplace Realities. MIT Press, Cambridge, MA

Booth B (1998) Understanding the information needs of visitors to museums. Museum Management and Curatorship 17(2):139-157, URL

Branschofsky M, Glavash K (2003) Mit,'s Dspace: a good fit for etd,'s. In: Schirmbacher P (ed) Proceedings of the Sixth International Symposium on Electronic Theses and Dissertations ETD2003 (Humboldt-Universität zu Berlin, 20.05.2003 - 24.05.2003), Humboldt-Universität zu Berlin, Berlin, retrieved from www.dspace.org/implement/community-workflow.pp

Bruebach N (2003) Archival science in germany - traditions, developments and perspectives. Archival Science 3(4):379-399

Buckland M (1992) Redesigning Library Services: A Manifesto. American Library Association, Chicago, URL http://sunsite.berkeley.edu/Literature/Library/Redesigning/pdf.html 
CALIMERA Project (2005) Calimera Guidelines: Digital preservation.

CALIMERA Project, retrieved from http://www.calimera.org/Lists/Guidelines

Casey ME, Savastinuk LC (2006) Library 2.0. Library Journal URL

http://www.libraryjournal.com/article/CA6365200.html

Cook T (2001) Archival science and postmodernism: new formulations for old concepts. Archival Science 1(1):3-24

Cook T, Schwartz JM (2002) Archives, records, and power: From (postmodern) theory to (archival) performance. Archival Science 2(3):171-185

Crawford W (2006) Library 2.0 and 'library 2.0'. Cites \& Insights 6(2):1-32, URL http://citesandinsights.info/civ6i2.pdf

Crofts N, Doerr M, Gill T, Stead S, Stiff M (eds) (2007) Definition of the CIDOC Conceptual Reference Model. ICOM/CIDOC Documentation Standards Group, continued by the CIDOC CRM Special Interest Group, retrieved from http://cidoc.ics.forth.gr/docs/cidoc_crm_version_4.2.2.pdf

Consultative Committee for Space Data Systems (CCSDS) CC (2002) Reference model for an open archival information system (OAIS). Blue book, Consultative Committee for Space Data Systems (CCSDS), Washington, DC

Cox, RJ (1998) Access in the digital information age and the archival mission: the United States. Journal of the Society of Archivists 19(1):25-40.

Cunningham A (2007) Digital curation/digital archiving: A view from the National Archives of Australia. In: DigCCurr 2007 International Symposium on Digital Curation, Chapel Hill, Chapel Hill, pp 18-20

Dingsøyr T, Røyrvik E (2003) An empirical study of an informal knowledge repository in a medium-sized software consulting company. In: ICSE ,'03: 
Proceedings of the 25th International Conference on Software Engineering, IEEE Computer Society, Washington, DC, pp 84-92

DRIVER Project (2007) DRIVER Digital Repository Infrastructure Vision for European Research. Available at http://www.driver-repository.eu

Duff, W (2002) Understanding the Information-seeking Behaviour of Archival Researchers in a Digital Age. Proceedings of the DLM-Forum.

Duff, W, Johnson, C (2002) Accidentally Found on Purpose: Information-Seeking Behavior of Historians in Archives. Library Quarterly 72(4):472-96.

Duff, W, Craig, B, Cherry, J (2004) Finding and Using Archival Resources: A Cross-Canada Survey of Historians Studying Canadian History. Archivaria 58:5180.

Duff W, Fox A (2006) You're a guide rather than an expert: Archival reference from an archivist's point of view. Journal of the Society of Archivists 27(2):129153

EAD Working Group (2002) Encoded Archival Description Tag Library Version 2002 - EAD Technical Document No. 2. Encoded Archival Description Working Group of the Society of American Archivists and the Network Development and MARC Standards Office of the Library of Congress, Chicago and Washington, DC, URL http://www.loc.gov/ead/tglib/index.html, retrieved from http://www.loc.gov/ead/tglib/index.html

Eales AB, Kvasnicka RM (eds) (2001) Guide to Genealogical Research in the National Archives, 3rd edn. National Archives and Records Administration, Washington, DC

Ebersbach A, Glaser M (2004) Towards Emancipatory Use of a Medium: The Wiki. International Journal of Information Ethics 2(11):1-9 
The digicult report: Technological landscapes for tomorrow's cultural economy. (2002) Tech. rep., European Commission, Directorate-General for the Information Society. http://www.digicult.info/pages/report.php

Fredriksson B (2003) Postmodernistic archival science - rethinking the methodology of a science. Archival Science 3(2):177-197

Gilliland-Swetland, A (1998) An exploration of K-12 user needs for digital primary source materials. The American Archivist 61(1):136-157.

Gilliland-Swetland, A, Kafai, Y, Landis, W (1999) Integrating Primary Sources into the Elementary School Classroom: A Case Study of Teachers Perspectives. Archivaria 48:89-116.

Greenwood DJ, Levin M (2000) Handbook of qualitative research, Sage, Thousand Oaks, CA, chap Reconstructing the relationships between universities and society through action research, pp 85-106

Hagen F (2007) Research Roadmap. Tech. rep., DigitalPreservationEurope (DPE). Retrieved from http://www.digitalpreservationeurope.eu/publications/dpe_research_roadmap.pdf Heikkinen R (2004) Kajaanin linna. Västiki vuosisatojen virrassa. Kainuun museo ja Lönnrot-instituutti, Jyväskylä

Hill, A (2004) Serving the Invisible Researcher: meeting the needs of online users. Journal of the Society of Archivists 25(2):139-148.

Hollingshead A, Fulk J, Monge P (2002) Fostering Intranet Knowledge Sharing: An Integration of Transactive Memory and Public Goods Approaches. MIT Press, Cambridge, MA 
Huvila, I (2006) The ecology of information work -- A case study of bridging archaeological work and virtual reality based knowledge organization. Diss. Åbo Akademi University. Åbo Akademi University Press: Åbo.

Initiative TDCM (2003) Information and documentation - the dublin core metadata element set ISO 15836:2003(E). Tech. rep., ISO, URL http://dublincore.org/documents/2006/12/18/dces/

Ithaka Harbors (2007) Portico Electronic Archiving Service. Ithaka Harbors, available at http://www.portico.org

Kemmis S, McTaggart R (2000) Handbook of qualitative research, Sage, Thousand Oaks, CA, chap Participatory action research, pp 567-605

Kensing F, Blomberg J (1998) Participatory design: Issues and concerns. Computer Supported Cooperative Work (CSCW) 7(3):167-185.

Ketelaar E (1992) Archives of the people, by the people, for the people. South Africa Archives Journal 34:5-16

Kivistö T (2007) Saaren kartanon arkiston arkistoluettelo. Koneen Säätiö and Muuritutkimus, Mietoinen, retrieved from http://saarenkartano.muuritutkimus.fi/index.php/Saari:Schema

Kostiainen E, Valtonen MR, Vakkari P (2003) Information seeking in pre-trial investigation with particular reference to records management. Archival Science 3(2):157-176

Kotelnikov M, Polonsky A, Kiesel M, Völkel M, Haller H, ad Pär Lannerö MS, Davis B (2007) Interactive semantic wikis. Deliverable D1.1, NEPOMUK Consortium, Kaiserslautern, retrieved from http://nepomuk.semanticdesktop.org/xwiki/bin/download/Main1/D1_NEPOMUK _Interactive_Semantic_Wikis.pdf 
Krötzsch M, et al (2005) Semantic Mediawiki. Retrieved from http://meta.wikimedia.org/wiki/Semantic_MediaWiki

Lankes RD, Silverstein J, Nicholson S (2007a) Participatory networks: The library as conversation. Tech. rep., Information Institute of Syracuse, Syracuse University,'s School of Information Studies, Syracuse, produced for the American Library Associations,' Office for Information Technology Policy

Lankes RD, Silverstein JL, Nicholson S, Marshall T (2007b) Participatory networks: The library as conversation. Information Research 12(4), URL http://InformationR.net/ir/12-4/colis05.html, retrieved from http://nformationR.net/ir/12-4/colis05.html

Lehtonen H (2004) Kajaanin linna 400 vuotta - kirjoituksia ja tutkimuksia linnan vaiheista. SKAS (3):47-50

Luyt B, Aaron TCH, Thian LH, Hong CK (2008) Improving wikipedia's accuracy: Is edit age a solution? Journal of the American Society for Information Science and Technology 59(2):318-330, URL http://dx.doi.org/10.1002/asi.20755

Lybeck J (2003) Archival education in Scandinavia. Archival Science 3(2): 97116.

Mark, G (2002) Extreme collaboration. Communications of the ACM 45(6):8993.

McGuinness D, Zeng H, da Silva P, Ding L, Narayanan D, Bhaowal M (2006) Investigations into Trust for Collaborative Information Repositories: A Wikipedia Case Study. In: Proceedings of the Workshop on Models of Trust for the Web. WWW 2006 Conference

McKemmish, S, Gilliland-Swetland, A, Ketelaar, E (2005) Communities of Memory: Pluralising Archival Research and Education Agendas. Archives and Manuscripts 33:146-174. 
Meijer A (2001) Accountability in an information age: Opportunities and risks for records management. Archival Science 1(4):361-372.

Meijer AJ (2003) Trust this document! ICTS, authentic records and accountability. Archival Science 3(3):275-290,

Menne-Haritz A (2001) Access - the reformulation of an archival paradigm. Archival Science 1(1):57-82, URL http://dx.doi.org/10.1023/A:1011508016557 Menne-Haritz A (2003) An archival system with old traditions in a time of change. Archival Science 3(4):321-327,

Moline, J, Otto, S (2004) User Study: Informational Needs of Remote National Archives and Records Administration Customers. NIST Special Publication 500221. DIANE Publishing: Darby, PA.

Mulrenin, A (2002) ed. The DigiCULT Report: Technological Landscapes for Tomorrow's Cultural Economy. European Commission, Directorate-General for the Information Society:Brussels.

OCLC, CRL (2007) Trustworthy Repositories Audit \& Certification: Criteria and Checklist, 1st edn. OCLC and CRL, Chicago and Dublin, $\mathrm{OH}$

Ontoprise, Institute AIFB, German Research Center for Artificial IntelligenceGerman Research Center for Artificial Intelligence (2007) Halo. Retrieved from http://ontoworld.org/wiki/Halo_Extension

Peddibhotla NB, Subramani MR (2007) Contributing to Public Document Repositories: A Critical Mass Theory Perspective. Organization Studies 28(3):327-346, 10.1177/0170840607076002, URL http://oss.sagepub.com/cgi/content/abstract/28/3/327, http://oss.sagepub.com/cgi/reprint/28/3/327.pdf

Pick, G (2001) National survey of visitors to British archives February 2001. PSQG: London. 
Ribeiro F (2001) Archival science and changes in the paradigm. Archival Science 1(3):295-310,

Raymond, M (2008) My Friend Flickr: A Match Made in Photo Heaven. Library of Congress Blog (2008/01/16). Library of Congress: Washington DC.

Koneen Säätiö (2007) Koneen Säätiö. Retrieved from http://www.koneensaatio.fi

Schuler D, Namioka A (1993) Participatory Design: Principles and Practices. Lawrence Erlbaum, Hillsdale, NJ

Semantic Mediawiki (2007) Special:Types. Semantic Mediawiki, retrieved from http://semantic-mediawiki.org/index.php/Special:Types

Sexton, A, Turner, C, Yeo, G, Hockey, S (2004) Understanding users: a prerequisite for developing new technologies. Journal of the Society of Archivists 25(1):33-49.

Sexton, A, Yeo, G, Turner, C, Hockey, S (2004) User feedback: testing the LEADERS demonstrator application. Journal of the Society of Archivists 25(2):189-208. (Sexton et al. 2004b)

Shankar K (2004) Recordkeeping in the production of scientific knowledge: An ethnographic study. Archival Science 4(3):367-382

Shilton, K, Srinivasan, R (2008) Participatory Appraisal and Arrangement for Multicultural Archival Collections. Archivaria 63:87-101.

Spiegel A, Evans M, Gram W, Diamond J (2006) Museum visitors' understanding of evolution. Museums \& Social Issues 1(1):69-86, URL

http://lcoastpress.metapress.com/content/118052385m813521

Suchman L (1993) Participatory Design: Principles and Practices, Lawrence Erlbaum, Hillsdale, NJ, chap Foreword, pp vii-ix 
Sundqvist, A (2007) The use of records - a literature review. Archives \& Social Studies 1(1):623-653.

Surowiecki J (2004) The Wisdom of Crowds. Doubleday, New York

Tazzoli R, Castagna P, Campanini S (2004) Towards a semantic wiki wiki web. In: Proceedings of the International Semantic Web Conference (ISWC)

Thomassen T (2001) A first introduction to archival science. Archival Science 1(4):373-385.

Tibbo, HR (2002) Primarily history: historians and the search for primary source materials. JCDL 02: Proceedings of the 2nd ACM/IEEE-CS joint conference on Digital libraries. ACM: New York, 1-10.

Toms, E, Duff, W (2002) I Spent 1/ 2 Hours Sifting Through One Large Box....: Diaries as Information Behavior of the Archives User: Lessons Learned. Journal of the American Society for Information Science and Technology 53(14):12321238.

Wareham E (2002) From explorers to evangelists: Archivists, recordkeeping, and remembering in the pacific islands. Archival Science 2(3):187-207,

Watkins, K (2006) Public Services Quality Group of the National Council on Archives Survey of Visitors to UK Archives 2006. IPF Market Research: Croydon.

Weinberger D (2007) Everything is miscellaneous. Times Books, New York Yakel, E (2000) Thinking Inside and Outside the Boxes: Archival Reference Services at the Turn of the Century. Archivaria 49:140-60.

Yakel, E (2002) Listening to Users. Archival Issues 26(2):111-127. 
Yakel, E, Torres, D (2003) AI: Archival intelligence and user expertise: Users and archival research. American Archivist 66(1):51-78.

Yakel, E (2005) Archives in the Era of Accessibility. Revista Lligall 23:117-132.

Yakel, E, Bost, L (1994) Understanding Administrative Use and Users in University Archives. American Archivist 57(4):596-615.

Yakel, E, Shaw, S, Reynolds, P (2007) Creating the Next Generation of Archival Finding Aids. D-Lib Magazine 13(5/6). 